\title{
Ecotoxicidade de agrotóxicos para macrófitas aquáticas
}

Ecotoxicity of pesticides for aquatic macrophytes

Ecotoxicidad de agrotóxicos para macrófitas acuáticas

Gledson Renan Salomão Mestrando em Engenharia Civil, UNESP - Ilha Solteira/SP, Brasil. gledson.salomao@hotmail.com

Juliana Heloisa Pinê Américo-Pinheiro Professora Doutora, Universidade Brasil (UNIVBRASIL), Brasil. americo.ju@gmail.com 
RESUMO

O Brasil é um dos maiores consumidores de agrotóxicos do mundo. Contudo, paralelo ao aumento do consumo desses produtos, elevou-se também as pesquisas voltadas para a toxicidade dos cursos d'água, visto que, a ecotoxicologia é uma grande aliada no controle e monitoramento do ecossistema aquático, reportando aos órgãos regulamentadores os reais riscos de contaminação por agrotóxicos e outras substâncias tóxicas. Sendo assim essa revisão buscou avaliar os riscos ambientais de macrófitas devido a contaminação da água por esses contaminantes químicos. O ambiente aquático é caracterizado pelo seu nível trófico bem definido, ou seja, um ecossistema subdividido em produtores, consumidores e decompositores, e o ser humano está incluído nessa cadeia. As macrófitas, plantas aquáticas, tem sido uma das mais comprometidas com o aumento da toxicidade nos corpos d'água, devido a sua alta sensibilidade, principalmente para com os herbicidas. Os elevados níveis de agrotóxicos no ambiente estão causando sérios problemas a essas plantas, inclusive levando-as a letalidade, além dos processos de bioacumulação e biomagnificação, este último diretamente relacionado ao ser humano. Portanto o controle e o monitoramento sobre o uso de agrotóxico são de fundamental importância, uma vez que o seu uso descontrolado tende a causar um problema de difícil reversão, dessa forma é essencial a continuidade desses estudos, bem como promover leis e regulamentações mais rigorosas para manter maior controle sobre todo o ecossistema aquático.

PALAVRAS-CHAVE: Pesticidas. Sensibilidade. Toxicidade. Impacto Ambiental.

\section{ABSTRACT}

Brazil is one of the largest consumers of pesticides in the world. However, in parallel with the increase in the consumption of these products, there has also been increased research on the toxicity of water courses, since ecotoxicology is a great ally in the control and monitoring of the aquatic ecosystem, reporting to regulators the real risks contamination by pesticides and other toxic substances. Therefore, this review sought to evaluate the environmental risks of macrophytes due to the contamination of water by these chemical contaminants. The aquatic environment is characterized by its well defined trophic level, that is, an ecosystem subdivided into producers, consumers and decomposers, and the human being is included in that chain Macrophytes, aquatic plants, have been one of the most committed to the increase of toxicity in water bodies, due to their high sensitivity, especially to herbicides. The high levels of agrochemicals in the environment are causing serious problems to these plants, including leading to lethality, in addition to the processes of bioaccumulation and biomagnification, the latter directly related to humans. Therefore, the control and monitoring of the use of pesticides are of fundamental importance, since their uncontrolled use tends to cause a problem of difficult reversion, thus, the continuity of these studies is essential, as well as to promote stricter laws and regulations for maintain greater control over the entire aquatic ecosystem.

PALAVRAS-CHAVE: Pesticides. Sensitivity. Toxicity. Environmental impact.

\section{RESUMEN}

Brasil es uno de los mayores consumidores de agrotóxicos del mundo. Sin embargo, paralelo al aumento del consumo de estos productos, se aumentó también las investigaciones dirigidas a la toxicidad de los cursos de agua, ya que la ecotoxicología es una gran aliada en el control y monitoreo del ecosistema acuático, reportando a los órganos reguladores los reales riesgos de contaminación por agrotóxicos y otras sustancias tóxicas. Siendo así esta revisión buscó evaluar los riesgos ambientales de macrófitas debido a la contaminación del agua por esos contaminantes químicos. El ambiente acuático se caracteriza por su nivel trófico bien definido, es decir, un ecosistema subdividido en productores, consumidores y descomposiciones, y el ser humano está incluido en esa cadena. Las macrófitas, plantas acuáticas, han sido una de las más comprometidas con el aumento de la toxicidad en los cuerpos de agua, debido a su alta sensibilidad, principalmente a los herbicidas. Los altos niveles de agrotóxicos en el ambiente, están causando serios problemas a esas plantas, incluso llevando a la letalidad, además de los procesos de bioacumulación y biomagnificación, este último directamente relacionado al ser humano. Por lo tanto, el control y el monitoreo sobre el uso de agrotóxicos son de fundamental importancia, ya que su uso descontrolado tiende a causar un problema de difícil reversión, por lo que es esencial la continuidad de estos estudios, así como promover leyes y regulaciones más rigurosas para mantener un mayor control sobre todo el ecosistema acuático.

PALAVRAS-CHAVE: Los pesticidas. Sensibilidad. Toxicidad. Impacto ambiental. 


\section{INTRODUÇÃO}

Tem-se notado atualmente um crescente aumento no desenvolvimento de pesquisas relacionadas ao meio ambiente, visto que é implícito o quão impactante tem sido as atividades antropogênicas nesse meio. A ideia de que o tratamento de água resolve todas as situações tem mudado para a percepção de que os corpos hídricos são ecossistemas complexos requerendo a integração de diferentes áreas do conhecimento - e que um monitoramento mais eficiente deve enfatizar a preservação das fontes de abastecimento e das reservas naturais de recursos hídricos (BUSS et al., 2008).

Para tanto, há uma área que vem se destacando em relação aos estudos de impactos gerados pelo ser humano à natureza, que é o estudo da toxicologia, sendo que há diversos ramos, sendo eles: toxicologia clínica, forense e ambiental (OLIVI et al., 2008).

Segundo Zakrzewski (1994), a ecotoxicologia aquática se preocupa com o destino dos agentes tóxicos, seus metabólitos e produtos de degradação no ambiente e nas cadeias alimentares, bem como o efeito desses contaminantes sobre os organismos e as populações, considerando que a sobrevivência humana depende do bem-estar de outras espécies e da disponibilidade de ar, água, solo e alimentos adequados.

A agricultura está diretamente relacionada aos impactos de toxicidade no ambiente aquático. O Brasil é o segundo maior produtor de alimentos no mundo, ficando atrás apenas dos Estados Unidos, e, consequentemente, é um dos maiores consumidores de agrotóxicos, aproximadamente 551 mil toneladas em 2016, com destaque para o uso dos herbicidas, que sozinho corresponde a $58,50 \%$ do consumo total (IBAMA, 2016). Por meio do uso desenfreado para combater pragas e ervas no campo, e muitas vezes sem controle, esses compostos acabam permanecendo disperso no solo por um grande período, e, posteriormente, são carregados por meio do escoamento superficial e da lixiviação até os corpos d'agua (PARK et al., 2017).

Os agrotóxicos detectados nos cursos d'água podem penetrar nos organismos aquáticos através de diversas formas e seu grau de acumulação depende do tipo de cadeia alimentar, da disponibilidade e persistência do contaminante na água e especialmente de suas características físicas e químicas (SPACIE; HAMELINK, 1985).

Dentre as espécies afetadas no ecossistema aquático, encontra-se as macrófitas, que são plantas aquáticas sensíveis, ótimos bioindicadores de toxicidade, devido a sua alta sensibilidade a diversos compostos, principalmente aos herbicidas. (PARK et al., 2017).

\section{OBJETIVO}

Avaliar por meio de uma revisão de literatura o risco ambiental e a toxicidade de agrotóxicos para macrófitas aquáticas. 


\section{ECOTOXICOLOGIA AQUÁTICA}

O uso do termo ecotoxicologia foi apresentado pela primeira vez em junho de 1969, durante uma reunião do "Committee of the International Council of Scientific Unions (ICSU)", em Estocolmo, pelo toxicologista francês René Truhaut (TRUHAUT, 1977).

A ecotoxicologia é uma área especializada da toxicologia ambiental que centra seus estudos nos efeitos ocasionados por agentes químicos e físicos sobre a dinâmica de populações e comunidades integrantes de ecossistemas aquático (RONCO et al., 2004). Segundo Buss et al. (2008), a ecotoxicologia aquática considera as respostas de organismos sentinelas (ou biosensores) por meio da realização de bioensaios para analisar suas respostas frente a uma exposição tóxica. O autor supracitado ressalta ainda que uma de suas aplicações potencialmente mais interessantes é na deteç̧ão de impactos em tempo real, ou seja, indicando os impactos no momento em que estão ocorrendo no ecossistema.

Os testes de ecotoxicidade permitem avaliar a contaminação ambiental por diversas fontes poluidoras, tais como: efluentes agrícolas, industriais e domésticos, sedimentos, medicamentos e produtos químicos em geral, assim como, avaliar a resultante de seus efeitos sinérgicos e antagônicos (LOMBARDI, 2004). A visão adotada no contexto da Ecotoxicologia, volta-se aos efeitos da toxicidade causada em organismos individuais, relacionadas. de acordo com a Ecologia do estresse, ou seja, avaliar as reações que determinado composto é capaz de produzir em determinada espécie exposta (VAN STRAALEN, 2003).

Tal conceito, afirma Magalhães e Ferrão Filho (2008), relaciona-se com a grande importância que o nicho ecológico assume à medida que os agentes tóxicos frequentemente interagem com fatores de estresse naturais, como temperatura, $\mathrm{pH}$, pressão osmótica e nutrição, principalmente quando os organismos estão nas bordas de sua amplitude ecológica, condições ambientais na qual o organismo pode sobreviver e reproduzir, tornando os efeitos dos toxicantes, nessa faixa, mais severos. Uma situação de estresse surge quando algum fator ambiental muda ou quando um organismo se encontra fora de seu nicho ecológico. Por definição, um organismo não pode crescer e reproduzir fora de seu nicho, mas pode sobreviver temporariamente.

A figura 1 apresenta as faixas de tolerância e níveis de atividade biológica requeridos para manter as funções vitais (sobrevivência, crescimento e reprodução) dos organismos sob um gradiente de condições ambientais ( $\mathrm{pH}$, temperatura, oxigênio dissolvido, substâncias tóxicas). 


\section{Periódica Eletrônica}

\section{Fórum Ambiental}

Volume 14, Número 2, 2018

da Alta Paulista

ISSN 1980-0827

Figura 1. Níveis e condições toleráveis mínimas exigidas para um organismo conseguir se reproduzir, crescer ou manter-se vivo.

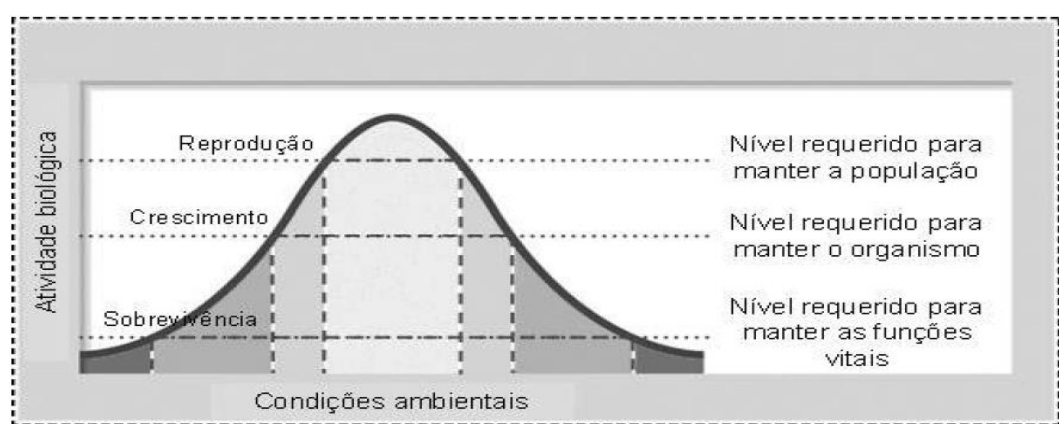

Fonte: Ricklefs (2001); Magalhães; Ferrão Filho (2008).

Quanto mais estreita a faixa de tolerância a condições ambientais, maior o nível requerido pelo organismo para sobreviver, crescer e reproduzir-se. Vale enfatizar, que testes que incluam estes principais processos biológicos, realizados em condições diferenciadas de exposição como por exemplo, variar os valores de $\mathrm{pH}$ e temperatura, são importantes na determinação dos efeitos de poluentes e contaminantes ambientais (MAGALHÃES; FERRÃO FILHO, 2008).

A exposição a um agente tóxico pode ser aguda, quando a concentração letal do agente é liberada em um único evento e rapidamente absorvida, ou crônica, quando o agente tóxico é liberado em eventos periodicamente repetidos, em concentrações subletais, durante um longo período de tempo (SCHVARTSMAN, 1991). Com isso, os ensaios de ecotoxicidade podem ser realizados para análise de toxicidade aguda e/ou crônica, para a escolha de um ou outro, deverá se levar em conta a necessidade do estudo.

\section{MACROFITAS AQUÁTICAS}

A escolha de um organismo modelo para testes de toxicidade depende da sensibilidade a poluentes específicos, há muitas espécies de zooplâncton, fitoplâncton e organismos macroscópicos sendo usado para este fim. Entre eles, as macrófitas aquáticas pertencentes à família Lemnaceae são modelos de organismos experimentais atraentes por um número de razões, incluindo a sua estrutura simples, pequena estatura, grau de homogeneidade, facilidade de cultura, alta taxa de crescimento e tempo de duplicação de 2 a 4 dias (HILLMAN, 1961; WANG; WILLIAMS, 1990; CHRISTEN; THEUER, 1996; KUMAR; HAN, 2010; LAHIVE et al., 2011; PARK et al., 2017).

Além disso, essas plantas têm importantes funções ecológicas e são amplamente distribuídas, e conhecidas por serem altamente sensíveis a substâncias orgânicas e inorgânicas, incluindo herbicidas, produtos farmacêuticos e metais, ficando um alerta sobre os grandes riscos dessas substâncias quando em contato com o meio aquático (WANG; WILLIAMS, 1990; LAHIVE et al., 2011;). 


\title{
Periódica Eletrônica
}

\section{Fórum Ambiental}

\author{
da Alta Paulista
}

Volume 14, Número 2, 2018

ISSN 1980-0827

As macrófitas são um grupo importante de produtores primários na base de hierarquias tróficas em ecossistemas aquáticos por isso a grande necessidade de estudo, já que qualquer impacto negativo sobre elas pode ter consequências duradouras, devido às alterações nos níveis tróficos, alterando a diversidade e funcionalidade do ecossistema aquático inteiro. Por essas razões, o teste de toxicidade laboratorial com macrófitas, especificadamente as espécies do gênero Lemna, é uma das principais metodologias de escolha para avaliar os impactos em águas doces. (MOODY; MILLER, 2005).

A figura 2 abaixo, apresenta os principais tipos de macrófitas aquáticas e a classificação das espécies da seguinte maneira: (a) Scirpus lacustris, (b) Phragmites australis, (c) Typha latifolia, (d) Nymphaea alba, (e) Potamogeton gramineus,(f) Hydrocotyle vulgaris, (g) Eichhornia crassipes, (h) Lemna minor, (i) Potamogeton crispus e (j) Littorella uniflora (BRIX; SCHIERUP, 1989).

Figura 2. Tipos ecológicos de macrófitas aquáticas.

I. Macrófitas aquáticas emersas

(a)
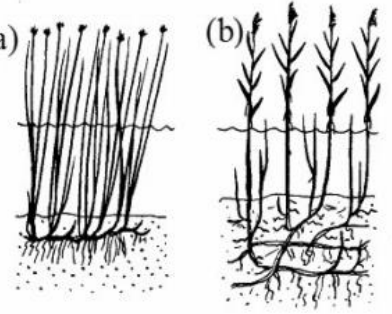

III. Macrófitas aquáticas flutuantes
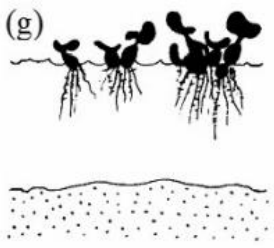

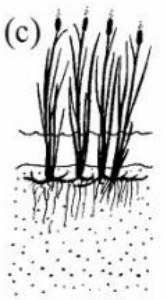

(h)

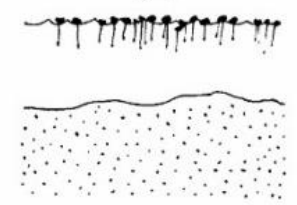

II. Macrófitas aquáticas com folhas flutuantes
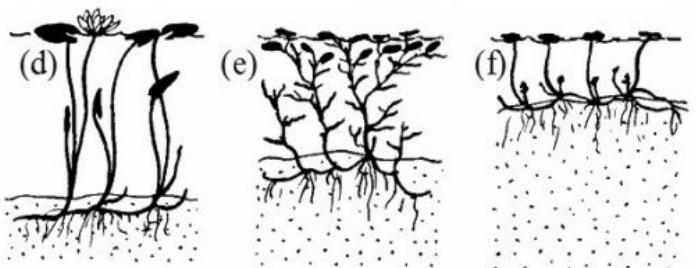

IV. Macrófitas aquáticas submersas

(i)

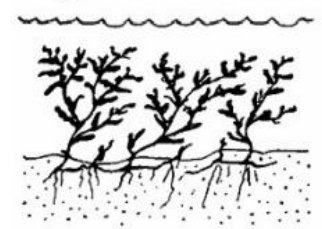

(j)

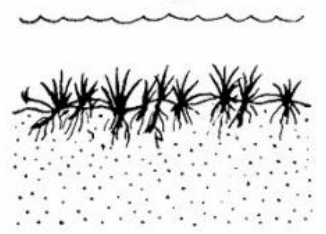

Fonte: (BRIX e SCHIERUP, 1989).

\section{CARACTERIZAÇÃO DOS AGROTÓXICOS}

As atividades relacionadas ao uso de agrotóxicos no Brasil, são regidas pela Lei $n^{\circ} 7802$ de 1989, regulamentada pelo Decreto no 4.074/2002, que traz em sua redação a caracterização de agrotóxico como sendo: 
Os produtos e os agentes de processos físicos, químicos ou biológicos, destinados ao uso nos setores de produção, no armazenamento e beneficiamento de produtos agrícolas, nas pastagens, na proteção de florestas, nativas ou implantadas, e de outros ecossistemas e também de ambientes urbanos, hídricos e industriais, cuja finalidade seja alterar a composição da flora ou da fauna, a fim de preservá-las da ação danosa de seres vivos considerados nocivos (BRASIL, 1989).

Após o uso na agricultura, seja na forma solida, liquida ou gasosa, o agrotóxico inicia reações físicas, químicas, físico-químicas e biológicas que podem influenciar no seu comportamento no ambiente. $O$ destino desses produtos é governado por processos de retenção (sorção), de transformação (degradação biótica e abiótica), de transporte (deriva, volatilização, lixiviação e carreamento superficial), e por interação desses processos (SPADOTTO, 2006). O quadro 1, apresenta os diversos meios de dispersão dos agrotóxicos no meio ambiente e seus agentes auxiliadores no transporte, bem como os processos, as consequências e os fatores que são capazes de armazenar as moléculas de agrotóxicos nos diferentes compartimentos ambientais (água, ar e solo) sem alterar sua estrutura.

Quadro 1. Meios de dispersão de agrotóxicos no solo e suas consequências.

\begin{tabular}{|c|c|c|}
\hline Processos & Consequências & Fatores \\
\hline Deriva & Movimento pela ação do vento & Velocidade do vento e tamanho das gotas \\
\hline Volatilização & $\begin{array}{l}\text { Perda por evaporação do solo, da planta } \\
\text { ou do ecossistema aquático }\end{array}$ & Pressão de vapor, velocidade do vento e temperatura \\
\hline Adsorção & $\begin{array}{l}\text { Remoção pela interação com plantas, solo } \\
\text { e sedimento }\end{array}$ & $\begin{array}{l}\text { Conteúdo mineral e matéria orgânica, tipo de mineral } \\
\text { e umidade }\end{array}$ \\
\hline Absorção & Absorção pelas raízes ou ingestão animal & $\begin{array}{l}\text { Transporte pela membrana celular, tempo de contato } \\
\text { e suscetibilidade }\end{array}$ \\
\hline Lixiviação & $\begin{array}{l}\text { Translocação lateral e vertical através do } \\
\text { solo }\end{array}$ & $\begin{array}{c}\text { Conteúdo de água, macroporos, textura do solo, } \\
\text { quantidade do mineral e conteúdo da matéria } \\
\text { orgânica }\end{array}$ \\
\hline Erosão & Movimento pela ação da água ou vento & $\begin{array}{c}\text { Chuva, velocidade do vento, tamanho das partículas } \\
\text { do mineral e da matéria orgânica com moléculas } \\
\text { adsorvidas }\end{array}$ \\
\hline
\end{tabular}

Fonte: PIERZYNSKI; SIMS; VANCE (1994)

Os agrotóxicos podem ser classificados de diversas maneiras, uma delas é de acordo com o modo de ação do ingrediente ativo no organismo alvo, podendo ser: acaricidas (ação em ácaros), bactericidas (ação em bactérias), fungicidas (ação em fungos), inseticidas (ação em insetos), herbicidas (ação em plantas daninhas), algicidas (algas), rodenticidas (roedores), entre outros (OLIVEIRA et al., 2013). 
A classificação dos agrotóxicos também pode ser feita de acordo quanto à periculosidade ambiental, em classes que variam de I a IV: produtos impeditivos de obtenção de registro, produtos altamente perigosos ao meio ambiente - Classe I; produtos muito perigosos ao meio ambiente - Classe II; produtos perigosos ao meio ambiente - Classe III; e produtos pouco perigosos ao meio ambiente - Classe IV (IBAMA, 1996). O quadro 2 apresenta a classe e a cor da faixa que deve ser anexada junto ao rótulo de produtos agrotóxicos para o consumidor saber qual a intensidade de toxicidade do produto que ele está adquirindo.

Quadro 2. Classificação toxicológica e cor da faixa em agrotóxicos.

\begin{tabular}{|c|c|c|}
\hline Classe Toxicológica & Toxicidade do Produto & Faixa indicativa de cor \\
\hline I & Extremamente tóxicos & Vermelha \\
\hline II & Altamente tóxicos & Amarela \\
\hline III & Mediamente Tóxicos & Azul \\
\hline Fonte: OPAS/OMS, 1997. & Pouco Tóxicos & Verde \\
\hline
\end{tabular}

Em 2016, de acordo com dados da a Associação Brasileira da Indústria Química (Abiquim), houve um faturamento líquido de 30 bilhões de reais com a venda de defensivos agrícolas. Observou-se uma redução de 6,3\% comparado com mesmo período em 2015, quando o faturamento líquido foi de 32 bilhões de reais (ASSOCIAÇÃO BRASILEIRA DE INDÚSTRIA QUÍMICA, 2016)

\section{IMPACTOS DOS AGROTÓXICOS PARA MACRÓFITAS AQUÁTICAS}

É de fundamental importância dizer que, durante a avaliação do risco ambiental considera-se que os organismos de um sistema natural são componentes de uma cadeia trófica. Dessa forma, é indispensável ponderar as inter-relações existentes nos diferentes níveis tróficos integrantes da pirâmide energética, em outras palavras, há uma grande interação desde o produtor até o consumidor final, que pode ser consumidor terciário, quaternário entre outros. A avaliação do risco tem por objetivo proteger as funções das populações, comunidades e ecossistemas (AZEVEDO; CHASIN, 2003).

A intoxicação do ecossistema aquático, por agrotóxicos, pode ser de caráter letal ou subletal, as espécies mais vulneráveis aos processos de degradação são as que ocupam os níveis tróficos mais elevados da cadeia alimentar ou em cada nível trófico as sucessionais tardias, devido ao processo de biomagnificação e bioacumulação. Portanto, quanto mais elevado for o nível do organismo na cadeia alimentar, maior é a concentração de poluentes que podem afetar os humanos (COUTINHO, 2002). 
Os efeitos letais ou agudos envolvem respostas que interferem nos processos celulares intensamente, causando a morte rapidamente. Muitas vezes, podem se expressar através de respostas que antecedem a morte, como sufocamento e interferências nos movimentos dificultando a fuga de predadores ou a obtenção de alimento (AZEVEDO; CHASIN, 2003).

Os efeitos dos agrotóxicos sobre a vida aquática são preocupantes, causando intoxicações maciças ou insidiosas, pois podem perdurar na natureza durante longo tempo, e por isso são muito perigosos para a saúde pública. Os praguicidas, defensivos agrícolas ou agrotóxicos, como substâncias químicas que são, modificam e/ou inibindo a fisiologia normal dos organismos vivos (MATAQUEIRO, 2006).

Cruz et al. (2012) em seus ensaios de toxicidade aguda - concentração de Letalidade em $50 \%$ dos organismos amostrados durante sete dias (CL50;7dias) - realizados em ensaios padrão, com herbicidas, constatou que o Glifosato $\left(S \operatorname{Sout}^{\circledR}\right)$ é um dos mais tóxicos entre os herbicidas para macrófita Azolla caroliniana, além de ser um dos mais usados no país, enquanto o 2,4-D é o herbicida menos tóxico. Segundo Américo et al. (2015), no caso dos efeitos subletais, os agrotóxicos podem acumular-se em tecidos, alterar funções celulares, causar lesões histológicas, no caso de peixes, alterar comportamento afetando diretamente o sistema nervoso, ou indiretamente, afetando outras funções orgânicas como osmorregulação e metabolismo de hormônios sexuais.

A exposição crônica a estes contaminantes pode alterar os níveis tróficos mais superiores, como por exemplo, pode deprimir o crescimento e o processo reprodutivo, que é um dos processos mais afetados pela poluição. As alterações na função de um grupo de organismos em um ecossistema causam efeitos em outros grupos que sejam suas presas ou predadores (HEATH, 1995). Sendo assim os compostos químicos advindos dos agrotóxicos podem ser transferidos do fitoplancton para os peixes e posteriormente para os humanos (DAS; MUKHERJEE, 2003; BEGUM, 2005; BORGES, 2005).

Em seu trabalho sobre a sensibilidade/toxicidade das espécies de Lemnas expostas a herbicidas, Park et al. (2017) estudou os efeitos desses e constatou que atrazina, diuron e simazina são herbicidas inibidores do fotossistema II (PSII), enquanto o paraquat inibe o fotossistema I (PSI), todos inibindo o fluxo de elétrons na produção fotossintética, levando à redução da fixação de Gás Carbônico $\left(\mathrm{CO}_{2}\right)$ consequentemente prejudicando o crescimento da planta, pois inibe a produção fotossintética.

Boutin et al., (2014) em seu estudo sobre a exposição de macrófitas à pesticidas (Glifosato), afirma que as plantas, no resultado final, estavam saudáveis a nível macroscópico - a olho nu , não apresentando sintomas de clorose que pudessem estar relacionados à murcha das folhas que estiveram em contato com herbicidas. No entanto, foi possível observar que a presença de resíduos de glifosato induziu efeitos subletais em diferentes níveis dos organismos, como foi relatado em outras espécies no estudo. Os efeitos de herbicidas em plantas "não-alvo" estão emergindo como uma das questões centrais na conservação da biodiversidade (PEREZ et al., 2017). 


\section{CONSIDERAÇÕES FINAIS}

Não se pode dizer que os agrotóxicos, bem como seu uso são prejudiciais ao meio ambiente, mas sim a maneira com que tem sido aplicado na agricultura, sem o devido controle e de forma desenfreada, forma essa que vem causando alterações no ecossistema aquático, como foi abordado nessa revisão. O aumento nos níveis de toxicidade no meio aquático, principalmente pelos herbicidas traz consigo um grande risco às macrófitas aquáticas.

O princípio ativo do herbicida, por exemplo, é inativar o processo fotossintético de ervas daninhas, e quando em excesso no solo, esse é lixiviado até os corpos d'água, tendo o princípio ativo agindo nos organismos "não-alvo", como as plantas aquáticas, levando-as até a morte, ou causando efeitos subletais, que posteriormente poderão ser repassados aos organismos dos níveis tróficos mais elevados, até chegar no ser humano, por meio do processo de biomagnificação.

\section{REFERÊNCIAS}

AMERICO, J.H.P. et al. O uso de agrotóxicos e os impactos nos ecossistemas aquáticos. ANAP Brasil. v. 8, n.13, p. 101-115, 2015.

ASSOCIAÇÃO BRASILEIRA DA INDÚSTRIA QUÍMICA. O desempenho da indústria química brasileira em 2016. Disponível em: <https://abiquim.org.br/includes/pdf/indQuimica/livreto-de-dados-2016-paginas.pdf>. Acesso: 31 mai. 2018.

BEGUM, G. In vivo biochemical changes in liver and gill of Clarias batrachus during cypermethrin exposure and following cessation of exposure. Pesticide Biochemical and Physiology, v. 82, p. 185-196, 2005.

BORGES, A. Valores hematológicos e bioquímicos séricos, efeitos de doses subletais da cipermetrina e características físico-químicas do sêmem do Jundiá Rhamdia quelen. Porto Alegre, 2005. 175 f. Tese (Doutorado em Ciências Biológicas) - Universidade Federal do Rio Grande do Sul, 2005.

BOUTIN, C. et al. Herbicide impact on non-target plant reproduction: what are the toxicological and ecological implications. Environmental. Pollution, p. 295-306. 2014.

BRASIL. Lei $n^{\circ} 7802$, de 11 de julho de 1989. Dispões sobre a pesquisa, a experimentação, a produção, a embalagem e rotulagem, o transporte, o armazenamento, a comercialização, a propaganda comercial, a utilização, a importação, a exportação, o destino final dos resíduos e embalagens, o registro, a classificação, o controle, a inspeção e a fiscalização de agrotóxicos, seus componentes e afins. Diário Oficial da União. Brasília, DF, 12 jul. 1989.

BRIX, H.; SCHIERUP, H.H. The use of aquatic macrophytes in water. Pollution control Ambio. v.15, p. 100-107, 1989.

BUSS, D.F. et al. Monitoramento biológico de ecossistemas aquáticos continentais. Oecologia brasiliensis. v.12, p. 339-345, 2008.

CRUZ, C. et al. Ecotoxicidade de herbicidas para a macrófita aquática. Planta Daninha. v. 30, p. 541-546, 2012. 


\section{Periódiea Eletrônica}

\section{Fórum Ambiental}

Volume 14, Número 2, 2018

ISSN 1980-0827

\section{da Alta Paulista}

CHRISTEN, O., THEUER, C. Sensitivity of Lemna bioassay interacts with stockculture period. Journal of Chemical Ecology. v.22 p. 1177-1186, 1996.

OLIVI, P. et al. A toxicidade em ambientes aquáticos: discussão e métodos de avaliação. Universidade de São Carlos. São Carlos. Química. Nova. v. 31, p.1820-1830, 2008.

COUTINHO, R. Programa Nacional da Biodiversidade: Pronabio projeto de conservação e utilização sustentável da diversidade biológica brasileira: Probio. Disponível em: <http://www.anp.gov.br/brnd/round6/guias/PE RFURACAO/PERFURACAO_R6/refere/Costoesrochosos.pdf>. Acesso em: 10 mai. 2018.

DAS, B. K.; MUKHERJEE, S. C. Toxicity of cypermethrin in Labeo rohita fingerlings: biochemical, enxymatic and haematological consequences. Comparative Biochemistry and Physiology, n. 134, p. 109-121, 2003.

HEATH, A.G. Water pollution and fish physiology. 2a ed. Lewis Publishers, Boca Raton.1995.

HILLMAN, W.S. The Lemnaceae or duckweed: a review of the descriptive and experimental literature. Botanical Review. v.27, p. 221-287. 1961.

INSTITUTO BRASILEIRO DO MEIO AMBIENTE E DOS RECURSOS NATURAIS RENOVÁVEIS (IBAMA). Portaria no 84, de 15 de outubro de 1996. Estabelece critérios a serem utilizados junto ao IBAMA, para efeito de registro e avaliação do potencial de periculosidade ambiental (ppa) de agrotóxicos, seus componentes e afins.1996.

INSTITUTO BRASILEIRO DO MEIO AMBIENTE E DOS RECURSOS NATURAIS RENOVÁVEIS (IBAMA). Boletins anuais de produção, importação, exportação e vendas de agrotóxicos no Brasil. 2016. Disponível em:

<http://www.ibama.gov.br/agrotoxicos/relatorios-de-comercializacao-de-agrotoxicos > Acesso em 30 mai. 2018.

KUMAR, K.S., HAN, T. Physiological response of Lemna species to herbicides and its probable use in toxicity testing. Toxicology and Environmental Health Sciences. v.02, p. 39-49. 2010.

LAHIVE, E. et al. Differential sensitivity of four Lemnaceae species to zinc sulphate. Environmental and Experimental Botany. v.71, p. 25-33. 2011.

LOMBARDI, J.V. Fundamentos de toxicologia Aquática In: Sanidade de organismos Aquáticos. Ranzani Paiva M.J.T, Takemoto R.M, Lizama M.A.P (Eds), Varela. São Paulo, 2004. 426p.

MAGALHÃES, D.P.; FERRÃO FILHO, A.S. A Ecotoxicologia como ferramenta no Biomonitoramento de Ecossistemas Aquáticos. Rio de Janeiro. RJ. Oecologia brasiliensis, v.12, p. 355-381, 2008.

MATAQUEIRO, M. I. Toxicidade aguda do triclorfom em pacus juvenis Piaractus mesopotamicus Holmberg, 1887). Jaboticabal, 2006. 68 f. Tese (Doutorado) - Universidade Estadual Paulista, Centro de Aqüicultura da UNESP Campus de Jaboticabal, 2006.

MOODY, M., MILLER, J. Lemna minor growth inhibition test. Small-scale Freshw.2005.

OLIVEIRA, T.G. et al. Agrotóxicos: Levantamento dos mais utilizados no oeste paulista e seus efeitos como Desreguladores Endócrinos. Fórum Ambiental da Alta Paulista. v. 09, p. 375-390, 2013.

OPAS (Organização Pan-americana da Saúde). Manual de vigilância da saúde de populações expostas a agrotóxicos. Ministério da Saúde, Secretaria de Vigilância Sanitária. Brasília: Organização Pan-americana da Saúde/OMS, 1997. Disponível em: <http://bvsms.saude.gov.br/bvs/publicacoes/livro2.pdf>. Acesso: 09 mai. 2018. 
PARK, J. et al. Comparing the acute sensitivity of growth and photosynthetic endpoints in three Lemna species exposed to four herbicides. Environmental Pollution. V. 220, p. 818-827, 2017.

PEREZ, D.J. et al. Can an aquatic macrophyte bioaccumulate glyphosate? Development of a new method of glyphosate extraction in Ludwigia peploides and watershed scale validation. Chemosphere. v.185, p. 975-982, 2017.

RONCO, A. et al. Em Ensayos Toxicológicos y Métodos de Evaluación de Calidad de Aguas - Estandarización, Intercalibración, Resultados y Aplicaciones; Morales, G. C., ed.; Centro Internacional de Investigaciones para el Desarrollo: Ottawa, cap.1. 2004.

SCHVARTSMAN. S. Intoxicações agudas. 4ạ ed. São Paulo. Sarvier, 1991. 355p.

SPACIE, A.; HAMELINK, J.L. Bioacumulation. In: RAND, G.M. \& PETROCELLI, S.R. Fundamentals of aquatic toxicology: methods and applications, New York: Hemisphere, 1985. p.495-525.

SPADOTTO, C. A. Avaliação de riscos ambientais de agrotóxicos em condições brasileiras. Documentos 58. EMBRAPA:CNPMA. 2006.

TRUHAUT, R. Ecotoxicology: objectives, principles and perspectives. Ecotoxicology and Environmental Safety. v.01, p.151-173, 1977.

VAN STRAALEN, N. M. Ecotoxicology bacomes stress ecology. Environmental Science and Tecnology. v.37, p. 324A330A, 2003.

WANG, W., WILLIAMS, J.M. The use of phytotoxicity tests (common duckweed, cabbage, and millet) for determining effluent toxicity. Environmental Monitoring and Assessment. v.14, p.45-58, 1990.

ZAKRZEWSKI, S. F.; Principles of Environmental Toxicology, American Chemical Society: Washington, 1994. 